\title{
Tubulin Polymerization Inhibitor CKD-516
}

National Cancer Institute

\section{Source}

National Cancer Institute. Tubulin Polymerization Inhibitor CKD-516. NCI Thesaurus. Code C101264.

A benzophenone derivative and water soluble valine prodrug of the tubulin binding agent S516, with potential tubulin-inhibiting, vascular-disrupting and antineoplastic activity. Upon administration, tubulin polymerization inhibitor CKD-516 is converted into its active metabolite S-516 that binds to tubulin and prevents its polymerization in tumor blood vessel endothelial cells and tumor cells. This blocks the formation of the mitotic spindle and leads to cell cycle arrest at the G2/M phase. As a result, this agent disrupts the tumor vasculature and tumor blood flow, deprives tumor cells of nutrients and induces tumor cell apoptosis. In addition, this agent has a direct cytotoxic effect on tumor cells by inhibiting tubulin polymerization. 